\title{
Sobre la reclusión, la corporalidad y las obligaciones de las mujeres en el Buenos Aires tardocolonial. Reflexiones a partir de un caso de desavenencia matrimonial
}

Resumen: Este artículo indaga, con base en un caso de desavenencia matrimonial, algunos de los sentidos a partir de los cuales se pretendía arbitrar el destino posible del cuerpo de las mujeres. El caso elegido nos permite tentar algunas preguntas e interpretaciones en relación a la corporalidad femenina, sus movimientos y conductas y, finalmente, las formas en las que se pretendía ejercer su control. Observamos cómo los códigos procedimentales y los lenguajes de los tribunales se sostienen sobre parámetros que tienden a docilizar los cuerpos femeninos para poder administrar justicia sobre ellos.

Palabras clave: justicia colonial, corporalidad, mujeres, antropología histórica.

\section{Seclusion, corporality and the obligations of women in late-colonial Buenos Aires: the analysis of a case of marital disagreement}

Abstract: Based on a case of marital disagreement, this article investigates some of the meanings that inform the arbitration of possible destinies of women's bodies. The chosen case allows us to ask questions and attempt interpretations about feminine corporality, movements and behaviors and the ways in which control was exercised on women's bodies. We observe how the procedural codes and the languages of the courts are based on parameters that tend to render feminine bodies docile in order to administer justice over them.

Keywords: colonial justice, corporality, women, historical anthropology.

\section{Sobre a reclusão, corporalidade e obrigações das mulheres no final do período colonial em Buenos Aires. Reflexões a partir de um caso de desavença conjugal}

Resumo: Este artigo pesquisa, a partir de um caso de desavença matrimonial, alguns dos sentidos a partir dos quais se pretendia arbitrar o possível destino do corpo das mulheres. 0 caso escolhido permite lançar algumas questões e interpretações com relação à corporalidade feminina, seus movimentos e condutas e, finalmente, as formas como se pretendia exercer seu controle. Observamos como os códigos processuais e as linguagens dos tribunais baseiam-se em parâmetros que tendem a docilizar os corpos femininos para poder administrar a justiça sobre eles.

Palavras-chave: justiça colonial, corporalidade, mulheres, antropologia histórica.

Cómo citar este artículo: Bettina Sidy, "Sobre la reclusión, la corporalidad y las obligaciones de las mujeres en el Buenos Aires tardocolonial. Reflexiones a partir de un caso de desavenencia matrimonial”, Trashumante. Revista Americana de Historia Socia/ 15 [2020]: 82-102.

DOI: 10.17533/udea.trahs.n15a04

Fecha de recepción: 23 de octubre de 2018

Fecha de aprobación: 26 de julio de 2019

Bettina Sidy: Doctora en Antropología por la Universidad de Buenos Aires. Investigadora asistente del Consejo Nacional de Investigaciones Científicas y Técnicas [CONICET] y docente de la Universidad Nacional de San Martín.

Correo electrónico: bettinasidy@gmail.com 


\title{
Sobre la reclusión, la corporalidad y las obligaciones de las mujeres en el Buenos Aires tardocolonial. Reflexiones a partir de un caso de desavenencia matrimonial $^{\star}$
}

\author{
Bettina Sidy \\ Introducción
}

El 13 de noviembre de 1807, luego de pasar un tiempo encerrada, doña Manuela

EVázquez huyó de la casa que compartía con su legítimo marido en la ciudad de Buenos Aires. Aquel evento desató un proceso judicial dedicado a dirimir el lugar en el que doña Manuela debía permanecer mientras se resolvía el conflicto entre los cónyuges. Cursaba un embarazo de unos cuatro o cinco meses, según el expediente. Ella quería quedarse en la casa de su madre, mientras que don Domingo Vidal, con quien estaba casada, buscó por todos los medios que volviese con él o que fuera puesta en depósito en alguno de los lugares destinados para tal propósito: la casa de algún familiar, una corporación religiosa, una casa de familia en la cual se emplease a la mujer o la Casa de Recogidas — si la hubiese en la ciudad o paraje que se tratase- Para lograr sus objetivos, las partes expusieron distintas versiones de los acontecimientos, así como diversas valoraciones sobre los comportamientos y las características de los actores intervinientes. ${ }^{1}$

* Esta investigación fue financiada por el Consejo Nacional de Investigaciones Científicas y Técnicas (CONICET) y se enmarca en el plan de trabajo: “Antropología de la violencia histórica. Estudios de caso para los ámbitos domésticos (Buenos Aires y su campaña en el periodo tardo colonial)". Asimismo, se inscribe en dos proyectos colectivos que también han obtenido financiación: PIP-CONICET (2017/0100085), "Cuerpos marcados, cuerpos productivos: clasificaciones, transformaciones y resistencias. De la colonia temprana a las repúblicas (Andes y Río de la Plata)" y FONCYT, 2018-2020, (PICT-2017-1409) que avanza sobre las mismas temáticas.

1. "Autos que sigue doña Manuela Vázquez mujer del Sargento veterano don Domingo Vidal sobre desavenencias en su matrimonio", Buenos Aires, 1807. AGNA, Buenos Aires, Sala IX, Tribunales Administrativos, legajo 23-7-1, exp. 653, ff. 1-52. El expediente consta de un conjunto de recursos administrativos presentados por las partes interesadas ante un juez —en este caso el gobernador- que debía resolver el conflicto entre los cónyuges. El cuerpo del expediente inicia con una serie de papeles presentados por Manuela Vázquez en los que busca acreditar los motivos de su 
Este artículo indaga en torno a las estrategias presentadas por los personajes involucrados en el conflicto, la información que ponen en juego a lo largo del proceso y los modos en los que se validaban o no las observaciones sobre los comportamientos de las partes, con el propósito de revisar algunos de los sentidos a partir de los cuales se pretendía arbitrar el destino posible del cuerpo de doña Manuela y el de tantas otras como ella. Asimismo, incorporaremos a la lectura del expediente algunos de los saberes médicos y médico-religiosos que se empezaban a consolidar hacia fines del periodo colonial hispanoamericano que referían a la corporalidad femenina, sus cuidados y tratamientos, y que influyeron también en el ejercicio de la justicia y el gobierno en aquella época. Cabe señalar que el caso se desenvuelve en una sociedad signada por profundas transformaciones culturales, sociales y políticas. Una sociedad de antiguo régimen como la porteña que, a pesar de haber sido recientemente elevada a capital virreinal, había crecido y se había consolidado en la periferia, alejada no solo del esplendor y el linaje de otras capitales, sino también -en buena medida - de ciertos parámetros sociales y familiares, habituada a formas más flexibles y fronterizas de ordenamiento cultural.

De esta manera, y para el desarrollo de este trabajo, resultan relevantes los aportes realizados por distintos teóricos provenientes de la historia del derecho que se han dedicado a caracterizar y analizar la cultura jurídica del periodo. ${ }^{2}$ Por otra parte, son sumamente importantes las indagaciones que realizaron Darío Barriera, Carlos Mayo, Osvaldo Barreneche, Silvia Mallo y Viviana Kluger en torno a la relación entre justicia y sociedad en la región rioplatense durante el periodo tardocolonial. ${ }^{3}$ A su vez, Jaqueline Vassallo revisa el desarrollo de los

separación, denunciando golpes de parte de su cónyuge. Luego de esta primera serie (que puede leerse como una estrategia de parte de Manuela para que le permitan permanecer en la casa de su madre) figura un conjunto de memoriales remitidos por Domingo Vidal al gobernador en los que solicitaba le fuera restituida su esposa. Para lograrlo, Vidal presentó testigos en diversas oportunidades. En primer lugar, para que acreditasen su buena conducta, cosa que hacen en general sus compañeros de armas. Luego sobre su conducta para con ella y sobre lo que sucedió el día en que se produjo la separación. Dos meses después de iniciado el conflicto, en enero de 1808, y viendo que los recursos hasta allí interpuestos no surtían el efecto deseado, Domingo Vidal presentó finalmente un conjunto de testigos destinados a probar la mala conducta, no ya de Manuela, sino de su madre (en cuya casa se hallaba residiendo aquella). Apenas un mes después, Manuela era llevada contra su voluntad a la casa de residencia. Todo el conflicto judicial se produjo entre las partes fue dirimido por el gobernador, a quien dirigieron los escritos presentados. Se entiende que el recurso de Manuela de acudir al obispo debió haber sido seguido por el pedido de divorcio, sin embargo, hasta el momento no hemos encontrado la documentación que valide dicha hipótesis.

2. Carlos Garriga, “Orden jurídico y poder político en el Antiguo Régimen”, ISTOR. Revista de Historia Internacional 16 (2004): 13-44; Antonio Manuel Hespanha, "Una nueva historia política e institucional", Revista Mexicana de Ciencias Políticas y Sociales 41.166 (1996): 9-45; Antonio Manuel Hespanha, La gracia del derecho: economía de la cultura en la Edad Moderna (Madrid: Centro de Estudios Políticos y Constitucionales, 1993).

3. Darío Barriera, "La ciudad y las varas: justicia, justicias y jurisdicciones (ss. XVI-XVII)", Revista 
estudios de género, por un lado, y de la historia del derecho, por el otro, para dar cuenta del estado del conocimiento en el campo e invitar a resignificar nuestros propios quehaceres académicos. ${ }^{4}$ En esta línea, diversas perspectivas teóricas han desplegado a la corporalidad como eje problemático, y vinculan una mirada de género a la perspectiva judicial. ${ }^{5}$ Autoras como María Eugenia AlbornozVázquez y Aude Argouse analizan en particular la violencia jurídica aplicada sobre las mujeres y sus cuerpos con base en principios sociales, teológicos y morales. ${ }^{6}$ Mientras que Alejandra Araya Espinosa examina el castigo físico para indagar en las concepciones de "persona" y "cuerpo" implícitas en él." En un reciente trabajo Lía Quarleri revisa la idea del castigo físico como potestad de justicia para analizar el modo en que el mismo era administrado de manera diferencial entre hombres y mujeres en las antiguas reducciones jesuíticas. ${ }^{8}$ Asimismo, resulta central el aporte de Romina Zamora para reflexionar en torno a las lógicas de corrección y castigo dentro del ámbito doméstico, el eje regulador que representaba el padre de familia y la forma en que aquello funcionaba de manera interdependiente con la casa como núcleo económico y productivo. ${ }^{9}$

de Historia del Derecho 31 (2003): 69-95; Carlos Mayo y otros, "Plebe urbana y justicia colonial: las fuentes judiciales. Notas para su manejo metodológico", Frontera, sociedad y justicia coloniales, eds. Noemí Girbal de Blacha y otros (La Plata: Facultad de Humanidades y Ciencias de la Educación, Universidad Nacional de La Plata, 1989); Silvia Mallo, "La mujer rioplatense a fines del siglo XVIII. Ideales y realidad", Anuario del IEHSV (1990): 117-132;Viviana Kluger, Escenas de la vida conyugal. Los conflictos matrimoniales en la sociedad virreinal rioplatense (Buenos Aires: Quórum, 2003); Silvia Mallo, La sociedad rioplatense ante la justicia. La transición del siglo XVIII al XIX (Buenos Aires: Archivo Histórico de la Provincia de Buenos Aires, 2004).

4. Jaqueline Vassallo, “¿Es posible hacer historia del derecho desde una perspectiva de género?”, Poblaciones históricas. Fuentes, métodos y líneas de investigación, coords. Dora Celton y otros (Río de Janeiro: Asociación Latinoamericana de Población, 2009) 427-437.

5. Existe una línea de estudios sobre corporalidad en la historia occidental. Por ejemplo, la obra coordinada por Jean-Jacques Courtine, Alain Corbin y Georges Vigarello, en la que se analiza el cuerpo desde una perspectiva religiosa, política y social tomando en cuenta sus usos, las sexualidades, la medicina, la salud y la enfermedad, entre otras cuestiones. Asimismo, autores como Arlette Farge, desde una perspectiva histórica, y David Le Breton, desde la antropología, abren a nuevas conceptualizaciones y formas metodológicas para pensar las formas corporales, sus contextos, sus condicionamientos y sus posibilidades. Véase Jean-Jacques Courtine y otros, coords., Historia del cuerpo, 2 vols. (Madrid:Taurus, 2005); Arlette Farge, Efusión y tormento. El relato de los cuerpos. Historia del pueblo en el siglo XVIII (Buenos Aires: Katz, 2008); David Le Breton, Antropología del cuerpo y modernidad (Buenos Aires: Nueva Visión, 2002).

6. María Eugenia Albornoz Vásquez y Aude Argouse, "Mencionar y tratar el cuerpo: indígenas, mujeres y categorías jurídicas.Violencias del orden hispano colonial,Virreinato del Perú, s. XVII-XVIII”, Nuevo Mundo Mundos Nuevos. Débats (2009). DOI: 10.4000/nuevomundo.53163 (22/05/2018).

7. Alejandra Araya Espinoza, "La pureza y la carne: el cuerpo de las mujeres en el imaginario político de la sociedad colonial”, Revista de Historia Social y de las Mentalidades 1-2.8 (2004): 67-90.

8. Lía Quarleri, "Castigos físicos y control de los cuerpos. Mujeres guaraníes, trabajo y poder colonial", Temas Americanistas 40 (2018): 239-264.

9. Romina Zamora, Casa poblada y buen gobierno: oeconomia católica y servicio personal en San Miguel de Tucumán, siglo XVIII (Buenos Aires: Prometeo Libros, 2017). 
Respecto al tratamiento que recibían las mujeres, distintos autores indican que fueron consideradas como seres ambiguos a las que se estimaba siempre al borde de la impureza y el pecado y de quienes dependía en gran medida la reproducción social. En este sentido, su comportamiento sexual era observado y contenido como medio imprescindible para mantener los límites sociales, la moderación, la castidad y el orden. Retomando a Araya Espinosa, en estos discursos las mujeres debían estar sujetas, encerradas, recatadas, recogidas en el espacio de sus propios cuerpos que, sin embargo, las mantenían en un estado de inestabilidad permanente. ${ }^{10}$ Se esperaba de las mujeres una gestualidad que diera cuenta del gobierno del espíritu por sobre la carne. ${ }^{11}$ Julia Tuñón, Mónica Ghirardi y Jaqueline Vassallo muestran los modos en que dichos controles eran ejercidos a partir de la institución del depósito y como consecuencia de ciertas ideas en torno a la "naturaleza femenina" que indicaban que la misma se debía circunscribir a los ámbitos domésticos, ser protegida, sujeta y controlada. ${ }^{12}$

Al mismo tiempo, es necesario señalar que en la experiencia cotidiana, y tal como explican distintas autoras, mientras se esperaba que las mujeres de la élite fueran protegidas y acompañadas, al interior de otros grupos sociales la realidad era muy diferente. ${ }^{13}$ De hecho, las limitaciones materiales hicieron

10. Araya 73.

11. Las líneas rectoras de ese ideal se cimentaron a lo largo de los años y la Iglesia católica tuvo, en particular desde el Concilio de Trento (1563), un lugar preponderante en la orientación de los comportamientos públicos y privados de las mujeres.

12. Julia Tuñón, comp., Enjaular los cuerpos. Normativas decimonónicas y feminidad en México (México: El Colegio de México, 2008); Mónica Ghirardi y JaquelineVassallo,"El encierro femenino como práctica. Notas para el ejemplo de Córdoba, Argentina, en el contexto de Iberoamérica en los siglos XVIII y XIX", Revista de Historia Social y de las Mentalidades 14.2 (2010): 73-101.

13. Silvia Mallo, "Justicia, divorcio, alimentos y malos tratos en el Río de la Plata, 1766-1857", Investigaciones y Ensayos de la Academia Nacional de Historia 42 (1992): 373-400; Mallo, "La mujer rioplatense" 117-132; Susan Socolow, Las mujeres en la América Latina colonial (Buenos Aires: Prometeo Libros, 2016); Susan Socolow, "Parejas bien constituidas: la elección matrimonial en la Argentina colonial, 1778-1810", Anuario del IEHSV (1990): 133-160; Ann Twinam, Vidas públicas, secretos privados. Género, honor, sexualidad e ilegitimidad en la Hispanoamérica colonial (Buenos Aires: Fondo de Cultura Económica, 2009); Jaqueline Vassallo, “¿Historia de las mujeres o historia de género? Una aproximación al estudio de las mujeres en la ciudad de Córdoba a fines del siglo XVIII”, Revista Dos Puntas 11 (2015):153178. Respecto a las tramas familiares que se presentan en el expediente, cabe destacar lo señalado por autores como Ricardo Cicerchia, Mónica Ghirardi, Pilar Gonzalbo Aizpuru y Sonya Lipsett-Rivera en torno a la familia como columna vertebral de la sociedad colonial, en general, y la rioplatense, en particular. Interesan aquí las relaciones personales y domésticas, ya que como sostiene Asunción Lavrin representan el punto de partida para entender formas más complejas de comportamiento social, así como el papel institucional jugado por la Iglesia y el gobierno en tanto mecanismos de control durante el siglo XVIII hispanoamericano.Véase Ricardo Cicerchia,"Formas y estrategias familiares en la sociedad colonial", Nueva Historia Argentina. La sociedad colonial, t. 2, dir. Enrique Tandeter (Buenos Aires: Editorial Sudamericana, 2000); Mónica Ghirardi, "Familia, poderes, instituciones y conflictos. Iglesias, preceptos y transgresiones. La vertiente americana”, Familia y organización social en Europa y América, siglos XV-XX, eds. Francisco Chacón Jiménez y otros (Murcia: Universidad de Murcia, 2007) 109-130; Mónica Ghirardi, "Familia y maltrato doméstico. Audiencia episcopal de Córdoba, 
imposible a la mayoría de las mujeres ajustarse a dicho ideal de "preservación" y, si bien la honra de una mujer estaba íntimamente vinculada al honor y a la posición social de la familia, tal como señala Mallo, la subordinación de la mujer a la autoridad masculina no parece haber sido nunca tan absoluta como se pretendía desde lo jurídico. ${ }^{14} \mathrm{Al}$ respecto, Vassallo ha estudiado la complejidad de la participación femenina en la vida cotidiana de la ciudad de Córdoba. Explica que la presencia de las mujeres en los espacios públicos de la ciudad — calles, plazas y otros lugares de socialización como la orilla del río y las pulperías - fue considerada tan necesaria como problemática para las sociedades patriarcales. ${ }^{15}$ Algunas de las contradicciones aquí esbozadas son visibles en las presentaciones judiciales que aquellas realizaron ya sea por malos tratamientos y sevicia, por desavenencias o porque directamente solicitaron el divorcio ante la justicia eclesiástica.

El caso de Manuela Vázquez no representa una excepcionalidad respecto a una cantidad de expedientes judiciales en los que mujeres maltratadas, abusadas o destratadas iniciaron acciones tendientes al divorcio y vieron en el depósito un posible alivio en su devenir cotidiano. Sin embargo, algunas de las características que aquí se presentan — como la participación de autoridades civiles y eclesiásticas, el embarazo de Manuela, la cantidad de testigos directos que tuvo la huida de aquella y las formas en que se refieren a los comportamientos de las dos mujeres involucradas (Manuela y su madre viuda), por mencionar solo algunas de ellas - nos habilitan a pensar algunas preguntas e interpretaciones relacionadas con la corporalidad femenina, sus movimientos y conductas y, finalmente, las formas con las cuales se pretendía ejercer su control. Este tipo de expedientes administrativos en los que las partes presentan sus posiciones ante un juez — en este caso el gobernadornos permiten, en definitiva, mensurar el lábil territorio en el que cohabitan lo tolerado y lo escandaloso, lo permitido y lo no permitido por los miembros de una comunidad determinada. A continuación, presentaremos una reconstrucción de los sucesos que llevaron a Manuela Vázquez a escapar de la casa que compartía con Domingo Vidal, para luego tratar de indagar sobre algunas de estas contradicciones y sus resoluciones en el plano judicial.

Argentina. 1700-1850", História Unisinos 12.1 (2008): 17-33; Pilar Gonzalbo Aizpuru, "La historia de la familia en Iberoamérica", Sin distancias. Familia y tendencias historiográficas en el siglo XX, eds. Francisco Chacón Jiménez y otros (Murcia / Bogotá: Universidad de Murcia / Universidad Externado de Colombia, 2003) 47-60; Pilar Gonzalbo Aizpuru, "Con amor y reverencia. Mujeres y familias en el México colonial”, Jahrbuch Für Geschichte Lateinamerikas 35 (1998): 1-24; Asunción Lavrin, coord., Sexualidad y matrimonio en la América hispánica: siglos XVI-XVIII (México: Consejo Nacional para la Cultura y las Artes / Grijalbo, 1991); Sonya Lipsett-Rivera, "Honor, familia y violencia en México", Gozos y sufrimientos en la Historia de México, coords. Pilar Gonzalbo Aizpuru yVerónica Zárate Toscano (México: El Colegio de México / Instituto de Investigaciones Dr. José María Luis Mora, 2007).

14. Mallo, "La mujer rioplatense" 123.

15. Vassallo, “¿Historia de las mujeres o historia de género?”153-178. 


\section{Los sucesos}

En noviembre de 1806 Manuela Vázquez y el sargento Domingo Vidal contrajeron matrimonio en la ciudad de Buenos Aires. Entre 1792 y 1803,Vidal había servido en el regimiento de infantería de la provincia de Buenos Aires y de allí pasó al de Voluntarios de Montevideo, con lo que cumplió servicio en la frontera con el Brasil. Antes de casarse había vivido cerca de cinco años en la casa del subteniente de infantería don Manuel Sánchez. Al momento de los sucesos que se relatan en el expediente desempeñaba tareas bajo las órdenes del sub inspector don Bernardo de Velasco. ${ }^{16}$ La vida adulta de Domingo estuvo signada por la compañía y la presencia de militares de distinto rango que sucesivamente le brindaron empleo, amistad y cobijo.

Durante los primeros meses de matrimonio, la pareja vivió en los fondos de la casa de la madre de doña Manuela. Pasado cerca de un año y con un embarazo en ciernes, Domingo alquiló un cuarto frente a la casa del ayudante mayor veterano don Francisco Ventura del Río, sujeto con quien compartía tareas laborales. Sin embargo, Doña Manuela no veía con buenos ojos la mudanza. Por una parte, extrañaba a su madre y a sus hermanas de quienes ahora vivía bastante alejada, por otra parte, sentía que el tránsito de la casa materna al pequeño cuarto de alquiler representaba un claro deterioro en su estilo de vida. ${ }^{17} \mathrm{La}$ intención de Vidal era clara. Pretendía apartar a su legítima esposa de la influencia materna, la que consideraba nociva y escandalosa, y alejarla también de las costumbres de aquella casa en la que se permitían, según él, continuas visitas masculinas que incluían el acceso a los aposentos de las jóvenes hermanas y el alquiler de uno de los cuartos a una pareja que convivía en "ilícita amistad". ${ }^{18}$ De ingresos acotados,Vidal repudiaba el hecho de que su suegra vistiera a sus hijas con cierto lujo y se permitía expresar públicamente sus sospechas respecto a la forma en que obtenía los medios necesarios para comprar dichos bienes. Estaba firmemente determinado a erradicar estas influencias de la vida y los comportamientos de su esposa y proveerle de una existencia de acuerdo a sus posibilidades materiales, que no alterara las buenas costumbres y los comportamientos adecuados a una mujer de su condición.

16. Decía uno de los testigos, "me consta que desde 801 hasta la fecha existe empleado en la secretaria de la subinspección general conduciéndose con la misma y logrando por ella que los señores inspectores hayan hecho de él buen concepto y estimación". "Autos que sigue doña Manuela Vázquez"f. 12. Se trataba del primer conjunto de interrogatorios mandado porVidal para demostrar su buena conducta.

17. Entre otras cosas denunciaba que su marido "no le había debido la fineza ni siquiera de un par de zapatos" y en otra parte sostenía que "estaba abochornada porque vivía en cuarto de alquiler a la calle”."Autos que sigue doña Manuela Vázquez” ff. 5 y 15.

18. "Una mujer llamada doña Francisca que tenía ilícita amistad con un sargento de blandengues el cual es casado, por cuya circunstancia no expreso su nombre teniendo con la concubina tres hijos, la menor de ellos ahijada de Vázquez". Al mismo tiempo, se decía que visitas "sospechosas [...] entran hasta los aposentos, aun cuando estén las hijas en la cama”. "Autos que sigue doña Manuela Vázquez" ff. 32 y 38. 
De esta manera se produjo la mudanza.Vidal puso a disposición de Manuela un esclavo a jornal — propiedad de su vecino Ventura del Río-, quien le haría todos los días la compra de modo que se evitaría el tener que callejear, con los riesgos que aquello implicaba para la reputación de una mujer casada ${ }^{19}$ Con estas acciones Vidal buscaba limitar lo más posible la participación de su mujer en la vida pública y su tiempo en la calle, habituarla a una nueva domesticidad en sus ritmos y quehaceres cotidianos que se restringiera también a los medios materiales disponibles. Doña Manuela, como ya mencionamos, no parecía muy convencida del estilo de vida que su marido le imponía. A fines de octubre de 1807, apenas un par de semanas después de la relocalización, huyó del cuarto de alquiler. A la fuerza,Vidal volvió a sacarla de la casa materna y viendo la resistencia que aquella oponía y el estado de alteración con el que amenazaba escandalizar a todo el vecindario, tomó por costumbre echarle llave a la puerta del cuarto con ella adentro.

Pese a ello, la tarde del 13 de noviembre de 1807 doña Manuela Vázquez logró huir de nuevo. Lo hizo con la ayuda de su madre a quien había alertado, probablemente, gracias a la asistencia de algún vecino o vecina que llegó a advertirle lo que estaba sucediendo. Vidal estaba cumpliendo funciones en las casas de Ventura del Río, frente al cuarto de alquiler, cuando empezó a escuchar los gritos de su suegra que demandaba la llave para dejar salir a su hija. Ante el bochorno que le representaban los gritos de aquella,Vidal le hizo llegar la llave de manos del esclavo que hacía las compras. Para ese momento, sin embargo, todos los vecinos de las casas y cuartos aledaños estaban al tanto de la situación. Aprovechó el estado de alerta general para evitar que Vidal volviese a encerrar a Manuela, y la madre retornó a la casa de Ventura del Río. A fuerza de gritos y golpes a la puerta logró que aquel saliese de la oficina. Con tono de voz elevada y — según algunos de los testigospalabras insultantes, lo acusó de haber traído a su hija para tenerla encerrada y castigada, limitada a esas cuatro miserables paredes. Ante el escándalo suscitado, el propio Ventura del Río salió a pedir silencio. Ya al tanto de los conflictos de la pareja, aquel no dudaba en calificar a Manuela de "caprichosa" y a su madre como a una persona dedicada a dar "destructivos consejos". ${ }^{20}$

19. Don José Ignacio de Merlos, quien fuera vecino colindante de la pareja, aseguraba que él: "se manejó con ella con la mayor prudencia, sin faltarle con lo necesario para su subsistencia, lo que compraba diariamente un esclavo del declarante". "Autos que sigue doña Manuela Vázquez" f. 9. Aquí también vemos el esfuerzo deVidal por demostrar su buena conducta a partir de un testigo relativamente cotidiano de la relación que mantenía con Manuela.

20. "y que habiendo tenido el nominado Vidal no sabe qué cuestión con su mujer se apareció de pronto la madre de esta y se la llevó consigo habiendo antes llegado a la casa del que declara llamando a Vidal para entregarle la llave de su vivienda con palabras tan descompuestas que le obligo a salir y hacerla callar a fin de evitar el escándalo que causaba en todo el barrio con sus descompuestas producciones que esto es cuanto sabe"; "montó en su pretensión con voces descompasadas y en tono despreciativo e insultante diciéndole finalmente a Vidal que había traído al cuarto a su dicha hija, para tenerla encerrada y castigarla". "Autos que sigue doña Manuela Vázquez" ff. 13 y 25. En este caso, la declaración forma parte del segundo conjunto de interrogatorios solicitado por Vidal en el cual buscaba validar su trato para con su cónyuge, así como 
Unos diez días después de estos sucesos doña Manuela acudió al obispo para denunciar los malos tratos propinados por Vidal. Probablemente se trató de una estrategia de parte de aquella para justificar y validar su permanencia en la casa materna. Denunció haber sufrido garrotazos en varias oportunidades y solicitó que se intimase a su consorte a devolverle su cama y algunas de sus ropas. Ante el reclamo de Manuela y luego de una entrevista con Vidal en la que no solo se mostró duro, terco y rústico en sus modos, sino que también admitió el empleo de castigos fisicos hacia su esposa, el obispo de Buenos Aires convalidó la permanencia de aquella en la casa de su madre e instó a aquel a pasar a vivir también en dicha casa hasta tanto todo se normalizara. Mandato con el que Vidal nunca cumpliría.

Por el contrario, determinado como estaba a limitar a su esposa al espacio doméstico, buscó acreditar su buena conducta en los tribunales civiles y demostrar la mala influencia que ejercía la casa materna sobre su mujer. Se dirimía aquí la potestad de Vidal sobre el cuerpo de Manuela y el o los lugares en los que le correspondía permanecer, habitar, transitar. ${ }^{21}$ Mientras tuvieron lugar los interrogatorios y las declaraciones de las partes, Manuela permaneció en la casa materna. Entretanto, Vidal reclamaba sistemáticamente que fuera puesta en depósito en la casa de niños expósitos o en otro lugar de su aprobación.

El 2 de febrero, día de la Candelaria, doña Manuela Vázquez se paseaba libremente con ropas nuevas y rodeada por su madre y hermanas. ${ }^{22}$ Sin embargo, aquella libertad de movimiento no perduraría en el tiempo. Apenas diez días después, en un episodio que se consigna como violento en el expediente, fue retirada de la casa materna y enviada a la de niños expósitos a cumplir su depósito mientras la causa por "desavenencia matrimonial" seguía su curso. Hacia el final del expediente, Manuela denunciaba que, debido al mal concepto que Vidal se había empeñado en probar en torno a ella y el daño que le había producido a su imagen pública, el ayudante consignado para llevarla se sintió con derecho a secuestrarla y apeló a la "injuria y vejamen", a pesar de lo avanzado de su embarazo. Observamos cómo los dichos de Vidal sobre las conductas y las actividades de Manuela sirvieron para justificar, finalmente, tanto la violencia como el

construir el relato de lo sucedido el día que Manuela había huido de la casa que compartían, es por eso que el conjunto de testigos está constituido por vecinos más o menos cercanos al cuarto de alquiler que compartía la pareja.

21. Los primeros siete declarantes citados para respaldar la conducta de Vidal compartían dos características generales, eran todos hombres y pertenecían todos ellos a alguno de los cuerpos militares de la región. Como ya mencionamos, respecto a los sucesos del 13 de noviembre,Vidal convocó a cinco testigos (tres mujeres y dos hombres) que presenciaron de manera directa los hechos por los cuales Vázquez acabó partiendo a la casa de su madre. Por último,Vidal presentó una serie de interrogatorios — siete en total- destinados a demostrar la conducta "escandalosa" de su suegra y la mala influencia que la misma representaba para la vida y la conducta de su propia esposa.

22. En otra parte del expedienteVidal señalaba que "hoy he sabido por una señora que mi citada mujer estaba el día de la candelaria en la puerta de su casa con el mayor desahogo y un traje completo a la inglesa, ropaje que antes no tenía la madre no puede sostener semejante porte, ella no puedo saber porque medios lo puede haber adquirido". "Autos que sigue doña Manuela Vázquez"f. 40. 
control ejercido sobre ella. A continuación analizaremos cómo fueron desplegados los distintos presupuestos, sentidos y principios que favorecieron este desenlace.

\section{2. "Las señales que llevaba en mi cuerpo"}

Al presentarse ante el obispo Manuela Vázquez iniciaba su declaración explicando que debido a:"algunas desavenencias en mi matrimonio procedentes de caprichos a que están expuestos algunos hombres que se niegan a dar oídos a la razón o algunas nimiedades contrarias a la sociedad dieron margen a que mi precitado marido cometiere la vileza de darme garrotazos sin más fundamento que su antojo". ${ }^{23}$

Como ya mencionamos acudía a la autoridad eclesiástica para dejar asentada la situación de maltrato y obtener el permiso para permanecer en la casa de su madre. Aunque no contamos con la documentación probatoria, es probable también que la audiencia con el obispo respondiera al interés de Manuela para dar inicio a un posible trámite de divorcio. ${ }^{24}$ Tal como explica Araya Espinosa, en la sociedad colonial, si bien se aplicaba el principio de predominio masculino a la ordenación de la vida social, este se hallaba en contradicción con el principio que igualmente ordena la protección de las mujeres contra la violencia excesiva de los hombres. ${ }^{25}$ Por ejemplo, el teólogo moral Martín de Torrecilla (1635-1709) entendía que era lícito el castigar moderadamente a las mujeres con el propósito de enmendar sus conductas, sin embargo, explicaba que "peca gravemente el marido que azota cruelmente a su mujer; porque no es esclava, sino compañera y humana". ${ }^{26}$ La situación se agravaba a partir del embarazo de doña Manuela. Entendía el religioso que Vidal mostraba una gran "rusticidad del trato con su mujer, castigándola con desembozo y peligro tal vez de aborto". ${ }^{27}$

Todas las expectativas depositadas sobre la mujer, su cuerpo y sus comportamientos, se ejercían con mayor vigilancia durante la gestación, pues se ponía en

\section{3. "Autos que sigue doña Manuela Vázquez" f. 4.}

24. El hecho de que doña Manuela Vázquez recurriese tanto al obispo como a los tribunales ordinarios encuentra al menos dos explicaciones, no necesariamente excluyentes entre sí. Por un lado, como ya mencionamos, cabe la posibilidad de que Manuela pretendiese el divorcio formal. En este caso y en relación a la Real Cédula del 22 de marzo de 1787 que prescribía que las consecuencias patrimoniales - la obtención de la cama y las ropas - de los divorcios entablados ante los tribunales eclesiásticos debían ser resueltas por los civiles. Aquella formaba parte de las distintas medidas y reformas llevadas a cabo por los borbones en pos de recortar la influencia de la Iglesia en los asuntos familiares. Véase Kluger 224. No obstante, cabe también preguntarse si no se trató de una estrategia disuasoria de parte de la propia Manuela para evitar que su esposo la removiese del amparo materno. Si se tiene en cuenta que tanto los trámites de divorcio implicaban costos económicos, sociales y, en cierta medida, morales sobre quienes los iniciaban como que la sociedad porteña — tal como señalamos— se desarrolló en la periferia de los cánones imperiales, cabe pensar que muchas parejas optaran por la separación de hecho, temas que requieren mayor estudio e investigación.

25. Araya 70.

26. Kluger 158 .

27. “Autos que sigue doña Manuela Vázquez” f. 2. 
juego la reproducción social. Según explica Giulia Galeotti hasta mediados del siglo XVIII el contenido de un útero materno era entendido solo un apéndice del cuerpo de la madre. ${ }^{28}$ La gestación no era entendida como una relación, ya que no se consideraba la existencia de dos entidades que fueran autónomas, muy por el contrario, era entendida como uno más entre los procesos fisiológicos femeninos. Sin embargo, con el avance de las ciencias y sus descubrimientos de la mano del Iluminismo la gestación y el feto pasaron a formar parte de la escena de lo público y fueron retirados de la esfera de decisión exclusivamente femenina. El desarrollo de novedosos conocimientos en el plano anatómico sumado a la invención de artefactos y a la experimentación favorecieron el que los embriones o fetos empezaran a ser considerados como entidades autónomas, con lo que se redefinía así también la función de la mujer a la luz de nuevos postulados, religiosos, filosóficos, médicos y políticos. ${ }^{29}$

Respecto a esto último es relevante considerar el lugar que dichos desarrollos ocuparon al interior de las políticas borbónicas implementadas en la segunda mitad del siglo XVIII tendientes a la promoción de la industria y al control y el crecimiento de la población. A las medidas con un cariz higienista como los intentos de remoción de los cementerios en los centros poblados, las cuadrillas de limpieza de las calles, el empedrado y la fundación de protomedicatos en distintas ciudades se sumaba también una cierta intervención de parte de las autoridades tanto civiles como religiosas sobre los cuerpos gestantes; el embarazo y el parto que empezaban a impactar en la región del Río de la Plata y, fundamentalmente, en Buenos Aires, recientemente elevada a capital virreinal. En este sentido en 1805 se publicó en territorio americano una real cédula que indicaba fundamentalmente dos cuestiones. ${ }^{30}$ Por un lado, la obligatoriedad de la ejecución de la operación cesárea toda vez que una mujer embarazada hubiera muerto a fin de bautizar al feto y así garantizarle la salvación, por el otro, funcionaba como un manual de instrucciones para cuando no hubiera facultativos disponibles. La cédula demarcaba una potestad absoluta de los agentes del gobierno - en este caso civiles y religiosos en conjunto- sobre el cuerpo femenino, dado que incluso, "aunque se ha prevenido que la operación debe ejecutarse cuanto antes, no por esto se dejara de hacer aunque hayan pasado muchas horas" y aun si el feto "fuese como un grano de cebada, si tiene movimiento se bautizará". ${ }^{11}$

28. Giulia Galeotti, Historia del aborto. Los muchos protagonistas e intereses de una larga vicisitud (Buenos Aires: Nueva Visión, 2004).

29. Narciso Esparragosa y Gallardo, Memoria sobre una invención fácil y sencilla para extraer las criaturas clavadas en el paso sin riesgo de su vida, ni ofensa de la madre, $y$ para extraer la cabeza que ha quedado en el útero separada del cuerpo (Nueva Guatemala: D. Ignacio Beteta, 1798). Además de consignarse el invento creado por el autor, se reseñan toda una serie de instrumentos como fórceps, tenazas y cintos destinados a intervenir en la situación del parto.

30. "Operación cesárea. Para que se ejecute en la forma que previene la instrucción que se acompaña”, Córdoba, 1805. AHPC, Córdoba, Gobierno, Cédulas Reales, ff. 1-22.

31. "Operación cesárea” ff. 12 y 15. 
Ahora bien, la cédula no solo se insertaba en un contexto general tendiente al registro, control y promoción de la productividad de las poblaciones, sino que, además, era producto de una época en que se venían dando discusiones, descubrimientos e indagaciones en torno al conocimiento anatómico, los cuales se cristalizaron en tratados médicos o religiosos y fueron los que inspiraron buena parte del contenido de la real orden. ${ }^{32}$ En particular nos interesa destacar el Tratado sobre la Embriología Sagrada, escrito por el padre Francesco Cangiamila. ${ }^{33}$ En él, el autor desarrolla, entre otras cosas, un conjunto de líneas que ordenan los comportamientos a seguir a fin de evitar los abortos involuntarios. Siendo la mujer, como ya mencionamos, un ser voluble y débil, sujeto a múltiples tentaciones y descuidos era preciso señalar las actitudes y los comportamientos que se debían evitar. Si bien atribuía como primera causal de aborto involuntario "los maltratos ejercidos por los maridos", la responsabilidad de aquellos pareciera terminar alli. ${ }^{34}$ Le siguen siete causales que el cura enumera y que no solo son absoluta responsabilidad de las mujeres, sino que, además, se trata, según él, de "la inclinación natural de aquellas", inclinación que hay que corregir, circunscribir, domesticar. Entre las conductas dañinas que el autor enumera se encuentran viajar y llevar pesadas cargas, excesos en la comidas y bebidas, todas cuestiones asociadas a la "destemplanza o el poco cuidado de su salud" y a la "imprudencia y temeridad". Se previene a las mujeres de "las quejas, las riñas, la ira y las otras pasiones" tan habituales en ellas y tan propensas a terribles efectos, lo mismo aplicaba a las danzas y bailes y los vestidos muy ajustados que las mujeres empleaban por pura vanidad "con el fin e parecer airosas y de buen talle". 35

En las palabras del cura se articulaban saberes y conceptualizaciones en torno a la figura de la mujer, sus tendencias "naturales" y en consonancia al rol que la sociedad -y por sociedad entendemos en este caso las instituciones de la misma, es decir: el matrimonio, la familia - debía cumplir respecto a la conducción de

32. Tanto Georges Vigarello como Alain Corbin analizan los cambios que se produjeron en los saberes médico-higiénicos entre los siglos XVII y XIX, demarcando un viraje de las teorías humorales a la profesionalización de las prácticas médicas y a la lenta transformación de la figura del cirujano, que pasa de ser un oficio bajo a uno de prestigio. Miguel Pablo Cowen nos ofrece un panorama del conocimiento obstétrico entre finales del siglo XVIII e inicios del XIX.Véase Georges Vigarello "Higiene corporal y cuidado de la apariencia fisica", Historia del cuerpo, vol. 2, coords. Jean-Jacques Courtine y otros (Madrid:Taurus, 2005) 281-294; Alain Corbin, El perfume o el miasma. El olfato y el imaginario social. Siglos XVIII y XIX (México: Fondo de Cultura Económica, 1987); Miguel Pablo Cowen, "El caso Verónica Pascal: medicina y mala praxis en la Buenos Aires Rivadaviana" (Ponencia, V Jornadas de Sociología, Universidad Nacional de La Plata, 2008).

33. Francesco Cangiamila, Embriológia sagrada, ó Tratado de la obligación que tienen los curas, confesores, médicos, comadres y otras personas de cooperar á la salvación de los niños que aún no han nacido, de los que nacen al parecer muertos, de los abortivos, de los monstruos, etc. (Madrid: Imprenta de Pantaleon Aznar, 1785). A los fines de este artículo, hemos trabajado con la edición de 1785, aunque sabemos que existieron al menos dos traducciones previas; una de 1772 publicada en Nueva España y otra de 1774 publicada en Madrid.

34. "La cólera y brutalidad de un marido, que carga á su esposa de baldones, y la maltrata demasiado". Cangiamila 13.

35. Cangiamila 3,4 y 6 . 
dichas tendencias. Se adjudicaba a las mujeres el abandonarse a los placeres de la música y la danza, de las ropas y los adornos costosos y se asumía también que estos comportamientos encarnaban, en el mejor de los casos, una forma potencial de violencia tanto más peligrosa cuando las mujeres en cuestión se encontraban ya dentro de las instituciones sociales destinadas a rectificar, domesticar y contener sus conductas. ${ }^{36}$

Por lo tanto, si bien Vidal recibió la reprimenda de parte del obispo por golpear a Manuela y poner en riesgo el embarazo, tienen mucho mayor espacio en el expediente las objeciones que directa o indirectamente se dirigen a las inclinaciones y actitudes de Manuela, así como la posición del marido como garante de la rectitud de aquella. En este sentido y en consonancia con lo que planteaba el padre Cangiamila,Vidal no solo se manifiesta en reiteradas oportunidades alterado por el tono escandaloso y el modo insultante en el que su suegra y su esposa se expresaban en público, sino que también denunciaba la música y los bailes, habituales en la casa de la madre de Manuela, y los tratos ilícitos que allí se permitían. ${ }^{37}$

Asimismo, apuntaba a las ropas y vestidos que llevaba Manuela Vázquez al preguntar: "Si mi mujer no tiene y se ha presentado en la calle con ropa más que arreglada a su clase y facultades. Que proporciones le conoce a mi dicha suegra para sostener en parte a sus hijas de lujo, como el que usan". ${ }^{38}$ Lo que refería a la presunta vanidad desplegada por las mujeres y, bajo una lógica similar a la presentada por Cangiamila, sembraba cierto recelo en torno a las intenciones femeninas. El manto de desconfianza que se extiende con la mención de aquellos paseos excede el atuendo y avanza sobre otro tipo de sospechas. En este sentido Vidal preguntaba en uno de los interrogatorios: "si después de hecha la capitulación y reunidos los enemigos en el Retiro ${ }^{39}$ no anduvo mi mujer su madre y hermanas

36. En 1773 los vendedores de bandola de la ciudad de Buenos Aires se defendían de los ataques de los tenderos señalando que su servicio beneficiaba a las familias al contener los consumos femeninos, porque de lo contario:"no es pequeño el daño de los mercaderes solos con las mujeres que por noche y día van a las tiendas en donde no hay como halla padres o hermanos que reprimen". A lo que aquellos respondían que "entrándose en las casas y poniendo a la vista las bandolas a las mujeres con persuasiones para que las compren, estas por el adorno y lucimiento y tal vez por la prontitud que hallan en fiarles los mercachifles, gastaran más de lo necesario". "Medidas contra los vendedores ambulantes. Autos que se siguen varios mercaderes contra los de bandola. Sobre impedir a estos que no vendan en las calles", Buenos Aires, 1773. AGNA, Buenos Aires, Sala IX, Comerciales, legajo 30-9-3, ff. 17 y 79.

37. "Autos que sigue doña Manuela Vázquez"f. 12.

38. "Autos que sigue doña Manuela Vázquez" f. 36. La observación de las ropas y demás adornos corporales como pruebas de actividades ilícitas o deshonrosas, especialmente de las mujeres de bajos recursos, es un tema recurrente en la sociedad colonial hispanoamericana. En 1716 el gobernador interino de Buenos Aires publicó un bando en el que denunciaba: "los grandes escándalos [...] que se causan en esta ciudad por los desórdenes del vestir de mulatas con galas que no son de su estado ni pueden costear con licito trabajo personal". "Negras y mulatas decreto prohibiendo el uso de prendas por escándalo", Buenos Aires, 1716-1717. AGNA, Buenos Aires, legajo 31-2-8, f. 11.

39. Se refiere a la capitulación hecha luego de las invasiones inglesas. 
paseando por entre ellos"..$^{40}$ La forma velada en que acusa a Manuela de adúltera hilando una serie de atributos exteriores nos indica al menos dos cuestiones. Por un lado, funciona como un elemento que justifica la reprimenda, el encierro y la manipulación violenta del cuerpo de Manuela, y registra más bien la obligación de Vidal en torno al control que debe ejercer sobre aquel. Por el otro lado, construye la línea que distingue lo apropiado de lo inapropiado y contribuye así al desarrollo de la argumentación y la defensa de Vidal, quien continuamente se presenta a sí mismo como garante de la moderación, el recato y los buenos modos. ${ }^{41}$

\section{3. "La honradez con que siempre me he manejado"}

Buena parte de la estrategia argumental de Vidal a lo largo del proceso estuvo signada por su interés por mostrarse a sí mismo como un individuo honrado, carente de vicios y sujeto a la moderación. Como alguien que confiaba en la potestad que la institución matrimonial le otorgaba para disponer sobre el destino de quien era consignada como su legítima esposa: "desde el momento que se caso depende de mí $[. .$.$] de consiguiente que debe ir a donde yo vaya; pero tan lejos ella de creerlo$ así; no ha tenido embarazo en decirme que si me voy a Montevideo que es a donde está mi regimiento; no me ha de seguir". ${ }^{42}$

Sobre la conducta de Vidal decía uno de los declarantes que "se ha manejado con la mejor conducta sin que en su vida y costumbres se halla observado la más leve nota que desdiga de la buena comportación con que siempre se ha conducido". Por lo que mostraba con "civilización no vulgar la ardua aplicación al desempeño de sus deberes, su moderación y ciega obediencia a los superiores". ${ }^{43}$ Parte de este trato honrado y correcto consistía también en buscar: "atraer a su mujer y separarla de la compañía de la madre, pero ya sea por injustos caprichos de aquella o más bien por los destructivos consejos de esta no lo puede conseguir". ${ }^{44}$ Esta declaración se reforzaba con otras que, en la misma línea, señalaban la entereza del comportamiento de Vidal frente al bochorno provocado por su suegra, sin cuestionar ni los motivos ni la potestad de Vidal para encerrar y golpear a Vázquez. Se establecía así una oposición entre el comportamiento del marido y el de la madre / suegra. Frente a esas influencias correspondía definir cuál era la más o menos nociva para la conducta y la contención de Vázquez y cuál era el espacio destinado a dicha contención o depósito. En este sentido, Vidal solicitaba:

40. “Autos que sigue doña Manuela Vázquez” f. 39.

41. Decía uno de los testigos presentados porVidal para dar cuenta de la huida de Manuela que si bien "todo lo que presencio Vidal con la mayor prudencia, manifestando después que no había querido salir por el escándalo que ya causaba su suegra y también por evitar el trance a que lo exponían sus insultos, no obstante que le hubiera sido muy fácil detener a su mujer". "Autos que sigue doña Manuela Vázquez" f. 19.

42. "Autos que sigue doña Manuela Vázquez" f. 17.

43. "Autos que sigue doña Manuela Vázquez" ff. 7 y 13.

44. "Autos que sigue doña Manuela Vázquez” f. 13. 
mandar que inmediatamente sin pérdida de momento se deposite dicha mi mujer en la casa de ejercicios, San Miguel, u otro paraje que Su Señoría tenga a bien destinar, en la inteligencia que contribuiré con la mitad de mi sueldo para este fin, pues por ningún motivo conviene subsista al lado de su mencionada madre, ni menos sea su depósito a elección de la referida mi mujer. ${ }^{45}$

Respecto a las características de la institución del depósito en el periodo, cabe señalar el aporte de diversas autoras. ${ }^{46}$ Se trataba de una medida procedimental de resguardo fisico de la esposa y del honor familiar que podía tener lugar en distintas circunstancias, por ejemplo, mientras se substanciaba el pleito de divorcio, como consecuencia de una sentencia del mismo o como una pena derivada por la transgresión a las normas matrimoniales. Como ya se mencionó, el depósito podía desarrollarse en diferentes lugares. Es importante considerar que tanto la Casa de Recogidas, en particular, como el depósito, en general, funcionaron idealmente como una suerte de prisión para las mujeres que iniciaban pleitos contra sus maridos, “el depósito implicaba resguardo y protección frente a la coacción que pudiesen sufrir de los maridos durante los pleitos de separación, pero también encierro, control, sujeción y disciplina. A través de esta figura judicial la mujer quedaba de hecho, asimilada al conjunto de pertenencias del marido, como el ganado y objetos inanimados". ${ }^{47}$

Se trataba de un modelo de clausura, con horarios y ejercicios espirituales, que se aplicaba a las mujeres en su condición ambigua en tanto eran consideradas seres sujetos a la falta y como depositarias de la moral y el orden social. No se trata necesariamente de corregir las conductas individuales, sino de construir un estándar y con él producir el poder patriarcal, sostenerlo, reproducirlo. No obstante, cabe señalar que en cada caso sujeto a depósito se solían producir también disputas respecto al lugar en que debía / podía llevarse a cabo, y en la práctica la separación de la casa resultaba conflictiva por distintas razones. Por ejemplo, en la demanda de divorcio entablada por doña Sebastiana Calvo contra su esposo don Juan Rodríguez en Buenos Aires en 1799, el esposo explicaba que a las mujeres había que colocarlas "en un lugar de seguridad, no el que ella pida, sino el que elija el marido que es el perjudicado para evitar toda suerte de sorpresas". Sin embargo, en la misma presentación denunciaba que "Doña Sebastiana Calvo ha tomado por reclusión la casa que le ha parecido y ha sido de su elección y no de la mía, ella entra y sale, va y viene, corre y se divierte, sea de día o sea de noche". ${ }^{48}$ Observamos que en algunos casos las mujeres veían el depósito como una posibilidad de escape respecto a la situación vivida en la casa marital, mientras que los maridos pugnaban por mantener el control sobre sus mujeres, sus cuerpos y sus movimientos. En el

45. "Autos que sigue doña Manuela Vázquez" f. 4.

46. Ghirardi y Vassallo 73-101.

47. Ghirardi y Vassallo 79.

48. "Demanda de divorcio. Doña Sebastiana Calvo contra su esposo Don Juan Rodríguez", Buenos Aires, 1799. AGNA, Buenos Aires, Sala IX, Tribunales Administrativos, legajo 40-7-01, f. 51. 
caso que venimos abordando, Vidal sostenía que su suegra "más bien quiere que su hija viva separada de su marido, que contribuir con sus consejos a que la mujer debe estar donde quiera que su marido esta en cuanto no se oponga al servicio de dios y desdiga a su clase". 49

En la decisión respecto al depósito de Manuela se condensan distintas variables que hacen a las formas que adquiere la autoridad masculina y su jerarquía en el sistema sociopolítico de antiguo régimen. Para las mujeres casadas,Vidal los enumera claramente: marido, dios, clase. En la disputa por el retiro de las mujeres de la esfera pública, en muchas oportunidades — como en nuestro caso- eran ellas las que lo pedían como resguardo ante la privación de la libertad o la violencia ejercida por los maridos durante la convivencia. En este caso, lo que solicitaba Vidal era que Manuela fuera retirada del espacio público y que en su lugar fuera llevaba a un ámbito que colaborara con la construcción de su domesticidad y que en ese movimiento se le restituyera / ratificara a él la autoridad en peligro. En este sentido, no debemos perder de vista la importancia del espacio de la casa como uno de los ámbitos centrales a la hora de construir sentidos identitarios y redes sociales. Tal como explica Vassallo, las mujeres "aparecieron como destinatarias de un discurso de la domesticidad (basado en el ideario de lo doméstico y el culto a la maternidad como máximo horizonte de realización) reforzado por normas jurídicas y escritos doctrinarios que acompañaron su exclusión de diversas prácticas sociales y, muy especialmente, del espacio público". ${ }^{50}$

La referencia constante a las voces escandalosas y al bochorno en las calles están en consonancia con las líneas directrices que se siguieron para pensar los principios del comportamiento y de la educación femenina en la América colonial. Al respecto, Elvira García Alarcón nos recuerda lo señalado por Luis Vives en la "Instrucción de la mujer cristiana" publicado en 1524, texto fundante del ideario hispanoamericano en torno al comportamiento femenino. En este texto se señalaba que "la mujer virtuosa debe ser casi invisible; el destierro de la vida pública es su espacio [...] la mujer perfecta es aquella que se ajusta al marco teórico de la quietud". 51

Ahora bien, la actitud de estas mujeres en las calles públicas no solo era cuestionada por lo que decían, sino también por el porte, la imagen de sí que presentaban al mundo social circundante y la referencia que aquella imagen debía hacer a sus clase y condición, el margen de "visibilidad", en términos de Vives, que se consideraba prudente. En la sociedad hispano colonial se establecía una relación directa entre la conducta femenina y el honor de la casa como concreción espacial de la familia. En este sentido se simbolizaba allí un cierto orden socio-religioso basado en la interseccionalidad entre género, etnia, clase y edad. La preocupación por la

49. "Autos que sigue doña Manuela Vázquez" f. 15.

50. Jaqueline Vassallo, "Delincuentes y pecadoras en la Córdoba tardo colonial", Anuario de Estudios Americanos 63.2 (2006): 98.

51. Elvira García Alarcón, “Luis Vives y la educación femenina en la América colonial”, América sin nombre 15 (2010): 114. Cursiva en el original. 
honorabilidad de la mujer, como agente central de la reproducción social —más aun de la mujer embarazada-, ha sido un tema de discusión en los distintos órdenes que organizaban la vida social. En este marco, es importante no limitar la idea de lo "doméstico" únicamente a la casa, en cuanto espacio cerrado. Se trata más bien de la realidad espacial en la que las mujeres se mueven, interactúan, hacen sus vidas, en un contexto en el que la frontera entre lo público y lo privado es porosa y muchas veces indiferenciada. Esta especificidad es importante porque no se refiere únicamente a la responsabilidad de las mujeres respecto a lo que sucede en el recinto familiar, sino que, además, las hace cargo del mantenimiento de un orden pacífico en los ámbitos de acción socialmente reconocidos como femeninos, el mundo doméstico y, potencialmente, en todos los espacios de intervención en los que son reconocidas como tales. En esta dirección entendemos que sentenciaba Vidal la conducta de su mujer al pedir a uno de los testigos que explicase si cuando las dos mujeres — madre e hija— se presentaron ante el notario: "si no contestó esta en un tono que pareció más bien de burla, que otra cosa; pues creyéndose el citado notario que lo iban a fallar las echo a la calle escandalosamente". ${ }^{2}$ Obediencia, silencio, retraimiento y clausura representan las virtudes que se conciben como específicas del mundo femenino, cuando se tensionan las instituciones que organizan a la sociedad, la conducta que esté por fuera de estos patrones ideales queda sujeta a la corrección.

\section{Reflexiones finales}

En el texto "Reflexiones sobre la educación de las mugeres", publicado en el Telégrafo Mercantil de Buenos Aires el 18 de octubre de 1801, se hablaba del "valor doméstico" como característica preminentemente femenina. Sostenían allí que aquel se formaba: "por la noble unión de un carácter dulce, y de una moderación, que nada le altera; estas son, pues, las qualidades de una buena madre de familia". ${ }^{53}$

A lo largo de estas páginas repasamos el proceso judicial por el cual Manuela Vázquez intentó salirse del espacio conyugal. También podría decirse que se trata del expediente en el cual Domingo Vidal busca recuperar el control sobre el cuerpo y los comportamientos de aquella. Lo hicimos explorando los vínculos entre las exposiciones, declaraciones e interrogatorios allí presentes con determinados saberes científico-religiosos y escritos de tipo filosófico que, a su vez, fundaron las políticas en torno a las poblaciones en general y a las mujeres en particular en el periodo abordado.

Resulta evidente en el pleito aquí analizado - y no es ninguna excepción — la sobre representación con la que cuenta la voz masculina. En este sentido y respecto al ámbito jurídico en el periodo tardocolonial y a la participación de las mujeres allí, Albornoz y Argouse señalan que en el sistema judicial mandaba un "imperati-

52. “Autos que sigue doña Manuela Vázquez” f. 36.

53. Socolow, Las mujeres 265. 
vo de existencia ajustada". ${ }^{4}$ Por ende, en su interior, los cuerpos femeninos no podían "des-comportarse", dado que el hacerlo implica la posibilidad de no ser oídas por los jueces, algo que está presente en el pleito cuando Vidal reseña el tono de burla con el que su mujer se presentó ante el notario y su consecuente expulsión. Los códigos procedimentales y los lenguajes de los tribunales se sostienen sobre parámetros que tienden docilizar los cuerpos femeninos para poder administrar justicia para ellos. Explican las autoras que en los fueros judiciales a las mujeres como a los indios se las visualizaba siempre como criaturas dependientes y sujetas, como entidades incompletas y en falta de algo.

La existencia de un ideario en torno a lo femenino regido por estos principios es evidente a lo largo del proceso aquí reseñado, como también resulta patente que más allá de la distancia entre dicho ideal y las prácticas cotidianas de los hombres y las mujeres a principios del siglo XIX, el escenario judicial tendió, al menos en este caso, a consolidarse detrás de aquellas líneas rectoras. En este sentido, pudimos observar los argumentos de Manuela para solicitar la intervención de la justicia ordinaria y eclesiástica, así como las estrategias desplegadas por su esposo para sostener su potestad plena sobre aquella. Gracias al expediente sabemos que Manuela había huido de su marido al menos en una oportunidad con anterioridad a los hechos aquí consignados, denotando una desconformidad más o menos duradera respecto a su vida marital. Sabemos que, si bien logró mantenerse en la casa materna durante varios meses, finalmente fue llevada a la Casa de Recogidas en un episodio bastante violento. Nos resta, por un lado, intentar rastrear su destino en otro tipo de expedientes y archivos y, por el otro, continuar avanzando en la lectura y el análisis de otros casos que sirvan para tensionar los elementos que aquí se presentan.

\section{Fuentes}

\section{Manuscritas}

Archivo General de la Nación, Buenos Aires (AGNA)

Sala IX

Archivo Histórico de la Provincia de Córdoba, Córdoba (AHPC)

Gobierno

\section{Impresas}

Cangiamila, Francesco. Embriológia sagrada, ó Tratado de la obligación que tienen los curas, confesores, médicos, comadres y otras personas de cooperar á la salvación de los niños que aún no han nacido, de los que nacen al parecer muertos, de los 
abortivos, de los monstruos, etc. Madrid: Imprenta de Pantaleon Aznar, 1785. Esparragosa y Gallardo, Narciso. Memoria sobre una invención fácil y sencilla para extraer las criaturas clavadas en el paso sin riesgo de su vida, ni ofensa de la madre, y para extraer la cabeza que ha quedado en el útero separada del cuerpo. Nueva Guatemala: D. Ignacio Beteta, 1798.

\section{Bibliografía}

AlbornozVásquez, María Eugenia y Aude Argouse. "Mencionar y tratar el cuerpo: indígenas, mujeres y categorías jurídicas.Violencias del orden hispano colonial,Virreinato del Perú, s. XVII-XVIII". Nuevo Mundo Mundos Nuevos. Débats (2009). DOI: 10.4000/nuevomundo.53163 (22/05/2018).

Araya Espinoza, Alejandra. "La pureza y la carne: el cuerpo de las mujeres en el imaginario político de la sociedad colonial". Revista de Historia Social y de las Mentalidades. 1-2.8 (2004): 67-90.

Barriera, Darío. "La ciudad y las varas: justicia, justicias y jurisdicciones (ss. XVIXVII)". Revista de Historia del Derecho 31 (2003): 69-95.

Cicerchia, Ricardo. "Formas y estrategias familiares en la sociedad colonial". Nueva Historia Argentina. La sociedad colonial. Tomo 2. Dir. Enrique Tandeter. Buenos Aires: Editorial Sudamericana, 2000.

Corbin, Alain. El perfume o el miasma. El olfato y el imaginario social. Siglos XVIII y XIX. México: Fondo de Cultura Económica, 1987.

Cowen, Miguel Pablo. "El caso Verónica Pascal: medicina y mala praxis en la Buenos Aires Rivadaviana”. Ponencia, V Jornadas de Sociología, Universidad Nacional de La Plata, 2008.

Farge, Arlette. Efusión y tormento. El relato de los cuerpos. Historia del pueblo en el siglo XVIII. Buenos Aires: Katz, 2008.

Galeotti, Giulia. Historia del aborto. Los muchos protagonistas e intereses de una larga vicisitud. Buenos Aires: Nueva Visión, 2004.

García Alarcón, Elvira. "Luis Vives y la educación femenina en la América colonial". América sin nombre 15 (2010): 112-117.

Garriga, Carlos. “Orden jurídico y poder político en el Antiguo Régimen”. ISTOR. Revista de Historia Internacional 16 (2004): 13-44.

Ghirardi, Mónica. "Familia y maltrato doméstico.Audiencia episcopal de Córdoba, Argentina. 1700-1850”. História Unisinos 12.1 (2008): 17-33.

. "Familia, poderes, instituciones y conflictos. Iglesias, preceptos y transgresiones. La vertiente americana”. Familia y organización social en Europa y América, siglos XV-XX. Eds. Francisco Chacón Jiménez y otros. Murcia: Universidad de Murcia, 2007.

Ghirardi, Mónica y Jaqueline Vassallo. "El encierro femenino como práctica. Notas para el ejemplo de Córdoba, Argentina, en el contexto de Iberoamérica en los siglos XVIII y XIX”. Revista de Historia Social $y$ de las Mentalidades 14.2 (2010): 73-101. 
Gonzalbo Aizpuru, Pilar."Con amor y reverencia. Mujeres y familias en el México colonial”. Jahrbuch Fur Geschichte Lateinamerikas 35 (1998): 1-24. . "La historia de la familia en Iberoamérica". Sin distancias. Familia y tendencias historiográficas en el siglo XX. Eds. Francisco Chacón Jiménez y otros. Murcia / Bogotá: Universidad de Murcia / Universidad Externado de Colombia, 2003.

Hespanha, Antonio Manuel. "Una nueva historia política e institucional”. Revista Mexicana de Ciencias Políticas y Sociales 41.166 (1996): 9-45.

- La gracia del derecho: economía de la cultura en la Edad Moderna. Madrid: Centro de Estudios Políticos y Constitucionales, 1993.

Kluger,Viviana. Escenas de la vida conyugal. Los conflictos matrimoniales en la sociedad virreinal rioplatense. Buenos Aires: Quórum, 2003.

Lavrin, Asunción. Coord. Sexualidad y matrimonio en la América hispánica: siglos XVI-XVIII. México: Consejo Nacional para la Cultura y las Artes / Grijalbo, 1991.

Le Breton, David. Antropología del cuerpo y modernidad. Buenos Aires: Nueva Visión, 2002.

Lipsett-Rivera, Sonya. "Honor, familia y violencia en México". Gozos y sufrimientos en la Historia de México. Coords. Pilar Gonzalbo Aizpuru y Verónica Zárate Toscano. México: El Colegio de México / Instituto de Investigaciones Dr. José María Luis Mora, 2007.

Mallo, Silvia. La sociedad rioplatense ante la justicia. La transición del siglo XVIII al XIX. Buenos Aires: Archivo Histórico de la Provincia de Buenos Aires, 2004. . "Justicia, divorcio, alimentos y malos tratos en el Río de la Plata, 17661857”. Investigaciones y Ensayos de la Academia Nacional de Historia 42 (1992): 373-400.

."La mujer rioplatense a fines del siglo XVIII. Ideales y realidad". Anuario del IEHSV (1990): 117-132.

Mayo, Carlos y otros. "Plebe urbana y justicia colonial: las fuentes judiciales. Notas para su manejo metodológico". Frontera, sociedad y justicia coloniales. Eds. Noemí Girbal de Blacha y otros. La Plata: Facultad de Humanidades y Ciencias de la Educación, Universidad Nacional de La Plata, 1989.

Quarleri, Lía. "Castigos físicos y control de los cuerpos. Mujeres guaraníes, trabajo y poder colonial”. Temas Americanistas 40 (2018): 239-264.

Socolow, Susan. Las mujeres en la América Latina colonial. Buenos Aires: Prometeo Libros, 2016.

. "Parejas bien constituidas: la elección matrimonial en la Argentina colonial, 1778-1810". Anuario del IEHSV (1990): 133-160.

Tuñón, Julia. Comp. Enjaular los cuerpos. Normativas decimonónicas y feminidad en México. México: El Colegio de México, 2008.

Twinam, Ann. Vidas públicas, secretos privados. Género, honor, sexualidad e ilegitimidad en la Hispanoamérica colonial. Buenos Aires: Fondo de Cultura Económica, 2009. 
Vassallo, Jaqueline. ¿¿Historia de las mujeres o historia de género? Una aproximación al estudio de las mujeres en la ciudad de Córdoba a fines del siglo XVIII". Revista Dos Puntas 11 (2015):153-178. . “EEs posible hacer historia del derecho desde una perspectiva de género?”. Poblaciones históricas. Fuentes, métodos y líneas de investigación. Coords. Dora Celton y otros. Río de Janeiro: Asociación Latinoamericana de Población, 2009.

. "Delincuentes y pecadoras en la Córdoba tardo colonial". Anuario de Estudios Americanos 63.2 (2006): 97-116.

Vigarello, Georges. "Higiene corporal y cuidado de la apariencia fisica". Historia del cuerpo. Volumen 2. Coords. Jean-Jacques Courtine y otros. Madrid: Taurus, 2005.

Zamora, Romina. Casa poblada y buen gobierno: oeconomia católica y servicio personal en San Miguel de Tucumán, siglo XVIII. Buenos Aires: Prometeo Libros, 2017. 